\title{
Good and poor readers' learning of verbal and pictorial paired-associate lists
}

WAYNE OTTO, KARL KOENKE AND CARIN COOPER, WISCONSIN RESEARCH AND DEVELOPMENT CENTER FOR COGNITIVE LEARNING, The University of Wisconsin, Madison, Wisc. 53706

The prediction that poor readers would make more errors than good readers when the items in a paired-associate list were presented verbally, but that there would be no difference when the items were presented pictorially was not supported. Poor readers made more errors in learning the list than good readers with both methods of presentation. Both groups made fewer errors with pictorial than with verbal presentations.

Studies generally have shown that even when the IQ scores of the two groups are comparable, good readers perform better than poor readers with paired-associate (PA) learning tasks (Walters \& Doan, 1962; Walters \& Kosowki, 1963; Giebink \& Goodsell, 1967; Otto, 1961, in press). However, when Cooper (1968) used a list of pictures of common objects paired to minimize associational bonds, she found no significant difference in good and poor readers' performance with the PA task. The explanation may be inherent in the fact that Cooper's list included pictures only, while the lists used in the other studies included words or word-like stimuli. The finding of Rohwer, Lynch, Levin, \& Suzuki (1967) that third and sixth graders unselected as to reading ability learned more pairs when PA items were pictures rather than words provides some support for this notion: The general advantage derived from responding to pictures might be even greater for poor readers, who have every reason to respond negatively to words.

The present study was done to determine whether verbal and pictorial presentations of items would differentially affect good and poor readers' performance with a PA task. The predictions were that (a) in general, good readers, fifth graders and Ss responding to pictorial items would make fewer errors in learning a PA list than poor readers, second graders, and Ss responding to verbal items, and (b) specifically, poor readers would make more errors than good readers with verbal items, but with pictorial items the performance of the two groups would not differ.

Subjects and Design. The Ss were good and poor readers from grades two and five in a small city school system. The 10 teachers involved were asked to identify all of their pupils whom they judged to be (a) in the average (90-115) intelligence range, and (b) in the upper and lower thirds of their classes in reading achievement. The teacher judgments were checked against California Test of Mental Maturity IQ scores and reading subtest scores from the Stanford achievement battery, and pupils whose test scores were in accord with the teacher judgments were considered potential Ss. From this pool of Ss, equal numbers of boys and girls from each reading level and each grade were assigned to the two treatment groups. Thus, the design was a 2 by 2 by 2 factorial, the independent variables being grade (second and fifth), reading ability (good and poor), and treatment (verbal and pictorial lists). Six boys and six girls were assigned to each cell, for a total of 96 Ss.

Materials and Procedure. The PA list included eight pairs of common objects-mop - cake, tree - hat, clock - house, fish - bed, cat - shoe, soap - fork, comb - glass, and cow - ball-which were verbally or pictorially represented on 4 in. $x 4$ in. squares of poster board. The pictures were line drawings from a first grade workbook and the words were hand printed in lower-case letters.

The Ss were tested individually. The cards were arranged in pairs and placed face down in a constant order to begin. The $E$ said, "There are pictures (words) on the other side of these cards. I'm going to show you two at a time. Look at them carefully." Each pair was exposed for 5 sec and turned face down again. Before the first actual trial, Ss were told, "Now I will mix up the order. When I point to a picture (word), I want you to tell me which picture (word) is underneath. Then I will show you so you can see if you were right or wrong; but if you take too long in answering I will show you anyway. So try to tell me what the picture (word) is before I show you. If you cannot remember, then take a guess. Do you understand?" Each stimulus card was turned over and displayed for about $5 \mathrm{sec}$; then the response card was turned over and placed beside the stimulus whether the $S$ had responded or not. The pairs were scrambled between presentations of the entire list, which allowed an intertrial interval of about $20 \mathrm{sec}$. The criterion was one errorless trial or a maximum of 20 trials.

Results and Discussion. An individual's score was his number of errors to criterion. Mean numbers of errors to criterion are given by grade, reading level and treatment in Table 1 . An analysis of variance of error scores revealed significant Grade $(F=19.01$, df $=1 / 80, p<.01)$, Reading Level $(F=4.37$, df $=1 / 80, p<.05)$, and Treatment $(F=7.17, \mathrm{df}=1 / 80, \mathrm{p}<.01)$ effects. Comparisons of means show that, as predicted, good readers made fewer errors than poor readers, fifth graders made fewer errors than second graders, and Ss responding to pictorial items made fewer errors than Ss responding to verbal items.

The interactions, however, were not in line with the prediction. The only significant interaction was Grade by Reading Level $(F=4.48$, df $=1 / 80, p<.01)$. Sheffé post-hoc comparisons showed that the second grade poor readers made more errors than any other group, which accounts for the interaction. That there was a difference between reading ability groups at the second grade level but not at the fifth grade level may be due to limited difficulty of the PA task; that is, the task may have been sufficiently difficult to discriminate between the second grade groups but not the fifth grade groups. The lack of a significant Treatment by Reading Level interaction is at odds with the prediction that poor readers would make more errors than good readers with verbal but not with pictorial items. Whatever differential rate of PA learning of good and poor readers existed was equally present with both verbal and pictorial presentations of items.

The present results are in line with earlier findings that good readers perform better than poor readers on a PA task and that children learn pictorially presented items more rapidly than verbally presented items. They are not in line with Cooper's finding that there was no difference between good and poor readers' PA learning with pictorially represented items. An even more troublesome fact is that while the present good and poor reading ability groups differed at the second grade level but not at fifth, Cooper's groups-which learned the same eight item list, but with pictorial presentations only-differed at the fourth grade level but not the second. Thus, the suggestion that the present fifth grade groups did not differ because the task was too easy would appear to be inappropriate. However, a post-hoc explanation is suggested because there may be methodological implications for future studies.

In both Cooper's study and the present study, one criterion for selecting Ss was an IQ score in the average (90-115) range. Cooper relied upon scores from the California Test of Mental Maturity for second graders and from the Science Research Associates Primary Mental Abilities Test for fourth graders; whereas, Ss in the present study were chosen on the basis of both California Test of Mental Maturity scores and teacher's judgments. The impact of the consideration of teacher judgments may have been to eliminate those students, particularly among the poor readers, who did not perform reasonably near their capacity on the group tests. If this is so, then Cooper's Ss probably were not as bright as the present Ss. Given an IO difference between the two samples, the relative difficulty of the PA task at a particular grade level would also differ. Thus, the task may have been too hard or too easy to discriminate at a given grade level, depending upon the intelligence 
Table 1

Mean Numbers of Errors to Criterion

\begin{tabular}{|c|c|c|c|c|}
\hline \multirow[b]{4}{*}{ Grade } & \multicolumn{4}{|c|}{ Treatment } \\
\hline & \multicolumn{2}{|c|}{ Words } & \multicolumn{2}{|c|}{ Pictures } \\
\hline & \multicolumn{2}{|c|}{ Reading Level } & \multicolumn{2}{|c|}{ Reading Level } \\
\hline & Good & Poor & Good & Poor \\
\hline 2 & 55.00 & 77.00 & 40.42 & 59.67 \\
\hline 5 & 42.67 & 40.92 & 30.75 & 32.25 \\
\hline
\end{tabular}

of the Ss in the sample. Perhaps, too, the discrepancy between the two studies with regard to differences in performance with the pictorial list is due to differences in intelligence between the two groups. While this post-hoc reasoning may or may not be accurate, the fact is that standard control of intelligence in studies where the performance of good and poor readers is compared is essential if results from different studies are to be comparable.

\section{REFERENCES}

COOPER, C. The relationships among reading ability, grade level, and syntactical mediation in paired-associate learning. Unpublished Master's thesis, University of Wisconsin, 1968.

GIEBINK, J. W., \& GOODSELL, L. L. Reading ability and associative learning for children with a visuomotor deficit. Unpublished manuscript, University of Wisconsin, 1967.

OTTO, W. The acquisition and retention of paired-associates by good, average, and poor readers. J. educ. Psychol., 1961, 52, 241-248.

OTTO, W. Color cues as an aid to good and poor readers' paired-associate learning. International Reading Association, 1967 Conference Proceedings, in press.

OTTO, W. Elementary pupils' use of cues in paired-associate learning. Psychology in the Schools, 1968, 5, 178-182.

ROHWER, W. D., Jr., LYNCH, S., LEVIN, J. R., \& SUZUKI, N. Pictorial and verbal factors in the efficient learning of paired associates. $J$. educ. Psychol, 1967, 58, 278-284.

WALTERS, R. H., \& DOAN, H. Perceptual and cognitive functions of retarded readers. J. consult. Psychol., 1962, 24, 355-361.

WALTERS, R. H., \& KOSOWKI, I. Symbolic learning and reading retardation. J. consult. PsychoL, 1963, 27, 75-82. 